\title{
KIT NM_000222.2:C.2466T>R
}

National Cancer Institute

\section{Source}

National Cancer Institute. KIT NM 000222.2:C.2466T>R. NCI Thesaurus. Code C155703.

A nucleotide substitution at position 2466 of the coding sequence of the KIT gene where thymine has been mutated to any purine (adenine or guanine). 